NBER WORKING PAPER SERIES

\title{
AN INVESTIGATION OF THE EFFECTS OF ALCOHOL CONSUMPTION AND ALCOHOL POLICIES ON YOUTH RISKY SEXUAL BEHAVIORS
}

\author{
Sara Markowitz \\ Robert Kaestner \\ Michael Grossman \\ Working Paper 11378 \\ http://www.nber.org/papers/w11378
}

\begin{abstract}
NATIONAL BUREAU OF ECONOMIC RESEARCH 1050 Massachusetts Avenue Cambridge, MA 02138
\end{abstract}

May 2005

The views expressed herein are those of the author(s) and do not necessarily reflect the views of the National Bureau of Economic Research.

(C2005 by Sara Markowitz, Robert Kaestner, and Michael Grossman. All rights reserved. Short sections of text, not to exceed two paragraphs, may be quoted without explicit permission provided that full credit, including $($ ) notice, is given to the source. 
An Investigation of the Effects of Alcohol Consumption and Alcohol Policies on Youth Risky Sexual Behaviors

Sara Markowitz, Robert Kaestner, and Michael Grossman

NBER Working Paper No. 11378

May 2005

JEL No. I0

\begin{abstract}
The problems of teen pregnancy, HIV/AIDS and the high rates of other sexually transmitted diseases among youth have lead to widespread concern with the sexual behaviors of teenagers. Alcohol use is one of the most commonly cited correlates of risky sexual behavior. The purpose of this research is to investigate the causal role of alcohol in determining sexual activity and risky sexual behavior among teenagers and young adults. This research also addresses the question of whether there are public policies that can reduce the risky sexual behavior that results in harmful consequences. Individual and aggregate level data are used to investigate these questions. Results show that alcohol use appears to have no causal influence in determining whether or not a teenage has sex. However, alcohol use may lower contraception use among sexually active teens.
\end{abstract}

Sara Markowitz

NBER

365 Fifth Avenue, 5th Floor

New York, NY 10016

and Rutgers University

smarkow@rutgers.edu

Robert Kaestner

Institute of Government and Public Affairs

University of Illinois at Chicago

815 West Van Buren Street, Suite 525

Chicago, IL 60607

and NBER

kaestner@uic.edu

Michael Grossman

NBER

365 Fifth Avenue, 5th Floor

New York, NY 10016-4309

and CUNY

mgrossman@gc.cuny.edu 
In recent years there has been widespread public concern with the sexual behavior of teenagers. Interest in this issue has been brought about mainly by the problems of teen pregnancy, AIDS and other sexually transmitted diseases (STDs). Teen rates of pregnancy and out-of-wedlock birth in the U.S. are high by historical standards and high relative to other developed countries. Between 1940 and 1994, the rate of out-of-wedlock birth among women aged 15-19 increased from 7 per 1000 to 46 per 1000, and even the much heralded decline since 1994 leaves the rate of out-of-wedlock birth at about where it was in 1990 (Stephanie J. Ventura and Christine A. Bachrach, 2000).

When compared to older adults, teenagers and young adults are particularly at risk for contracting a STD. The incidence of chlamydia and gonorrhea--the two most common reportable STDs--are highest among American teenagers and young adults. In 2002, chlamydia incidence was 297 per 100,000 population for persons of all ages, 1,483 for teenagers, and 1,610 for young adults (CDC 2003). Similar age disparities are found for gonorrhea, with incidence rates per 100,000 population of 125, 476, and 593, respectively. Moreover, approximately half of all new human immunodeficiency virus (HIV) infections in the United States occur among people under age 25 (CDC 2002). These statistics make clear that teenagers' sexual behaviors are adversely affecting their health and development.

An important question is whether there are public policies that can reduce the risky sexual behavior that results in these harmful consequences. One potential way is to take steps to reduce alcohol use among teens, for example, by more stringent regulation of teen alcohol use or by increasing the price of alcohol. Alcohol use is one of the most 
commonly cited correlates of risky sexual behavior. Numerous studies have shown a positive association between alcohol use and risky sexual practices (see Catherine Donovan and Robert McEwan 1995 for a review of this literature). Importantly, however, previous research has not established whether or not the association between alcohol use and sexual behavior is causal. The absence of such information undermines the formulation of effective public policies. In this paper, we investigate whether or not alcohol is a causal factor affecting sexual activity and risky sexual behavior.

\section{Research Design and Data}

Our objective is to obtain estimates of the association between alcohol use and risky sexual behavior that can plausibly be given a causal interpretation. Achieving our objective is complicated by two factors. First, an individual's sexual behavior and alcohol use may depend on a common set of personal and social factors, some of which are unmeasured. Second, the two behaviors may influence each other directly. To address these problems, we obtain estimates of the relationship between alcohol use and sexual behaviors using a variety of statistical methods that under certain assumptions can be given a causal interpretation. We examine three outcomes: 1) the probability that a teenager engaged in sexual intercourse; 2) whether birth control was used during intercourse; and 3) state-level STD rates. Analysis of the first two outcomes is accomplished using individuallevel data and a structural equation that relates risky sex to alcohol use and personal characteristics. This model directly estimates the relationship of interest. The 
analysis of state-level STD rates uses a reduced form model that relates

determinants of alcohol use (i.e. taxes and other alcohol regulatory policies) to the incidence of STDs. This model reveals the direct effect of policy instruments on an outcome of risky sex, while also providing indirect evidence for or against causality.

Individual-level data come from the first three waves of the National Longitudinal Survey of Youth, 1997 cohort (NLSY97) and the biennial Youth Risk Behavior Surveys (YRBS). The characteristics of each data set allow us to use different estimation techniques in each. The NLSY97 is a panel data set with a sample size of approximately 7,900 teenagers. The YRBS is a pooled cross section with a sample size of close to 58,000 .

\section{Estimation and Results of Individual-Level Data}

Using the NLSY97, we use bivariate probit and individual fixed effects to assess the strength of the association between alcohol use and the probabilities of having any sex and having risky sex. Risky sex is an indicator that is equal to one if the person was sexually active in the last year and used birth control less than $90 \%$ of the time, and is zero for both abstainers and sexually active respondent who use birth control at least $90 \%$

of the time. Alcohol use is measured by any use in the past 30 days and by episodes of binge drinking (five or more drinks at one time) in the past 30 days.

The bivariate probit is identified by assuming that the amount of selection on unobserved variables is equal to the amount of selection on observed variables (see Joseph G. Altonji, Todd E. Elder, and Christopher R. Taber 2000). We also estimate regressions for which values of the correlation coefficient $(\rho)$ are fixed in order to gauge 
how much selection on unobserved characteristics is necessary to eliminate the positive association between substance use and sexual behavior (see Michael Grossman, Robert Kaestner and Sara Markowitz 2004 for further details.) Results indicate that a relatively small amount of selection on unobserved characteristics will do so. Thus, unless there is very little selection on unobserved characteristics, there is little likelihood that the positive association between alcohol use or binge drinking and the probability of having sex is causal. The results of second estimation technique used, the time-invariant, person-specific effects, also casts doubt on the causal relationship from alcohol use and the probability of sexual activity. As compared to OLS models, the positive effects of the two measures of alcohol use are substantially reduced, but are not entirely eliminated.

Using the YRBS data, we examine the effects of alcohol and marijuana use on the probability of having sex, and as additional outcomes, the number of partners and birth control use conditional on being sexually active. Alcohol use is measured as the number of days in the past 30 that the respondent had at least one drink of alcohol and the number of days on which 5 drinks or more were consumed in one sitting. Our estimation strategy here is to compare results from OLS, instrumental variables (IV), and a reduced form model. The state-level instruments used in the IV and reduced form models are the tax on beer, the per capita number of licensed alcohol outlets, the monetary price of marijuana, and statutory penalties for marijuana use. (For further details, see Michael Grossman and Sara Markowitz, forthcoming.)

Our conclusion for the probability of having sex is the same as above-there appears to be no evidence suggesting a causal role of alcohol use in determining the probability of having sex. A similar conclusion is reached if the number of sexual 
partners among sexually active teens is considered. However, the IV and reduced form results both show that among sexually active teenage males and females, alcohol consumption lowers the probabilities of using birth control and condoms specifically.

The results from the two individual-level data sets consistently show little evidence to support the conclusion that alcohol use has a causal influence on the incidence of teenage sex. It appears that divergent conclusions are reached if the outcome under consideration is the probability of unprotected sex. However, these results are not directly comparable, as the dependent variable is defined differently in the two data sets. The indicator of risky sex in the NLYS97 sample includes sexually active and inactive respondents, while the similar indicator in the YBRS data includes only sexually active respondents. These definitions reflect different assumptions about decision making. When the sample is limited to sexually active respondents, we assume that alcohol has a differential impact on the decision to have sex versus the decision to use birth control. Analyzing the use of birth control on the full sample assumes instead that both decisions are made simultaneously. The resulting coefficients on alcohol use reflect both the decision to engage in sex and the decision of whether or not to use protection. The divergent effects of alcohol consumption on the probability of using birth control indicate that further research is necessary on the decisions making process regarding teenage sexual behaviors.

\section{Estimation and Results of Aggregate-Level Data}

Information on sexual habits gathered from individual-level survey data may suffer from the problems of underreporting or measurement error. Therefore, it is 
worthwhile to examine the role of alcohol consumption in contributing directly to an outcome of risky sex-- STD rates. We analyze rates of gonorrhea and AIDS as reported by the Centers for Disease Control for young males and females. The gonorrhea data are reported for each state from 1981 to 2001 for youth ages 15-19 and 20-24. The AIDS data are at the MSA level from 1982 to 2001. Rates by gender for ages 20-29 and 30-34 are analyzed. Since there is on average an 8 year lag between initial viral transmission and the development of symptomatic AIDS, these individuals most likely contracted the disease between the ages of 12-21 and 22-26 thus providing a sample of teenagers and young adults. In the AIDS equations, all independent variables are lagged 8 years so that the timing of the right-hand side variables is consistent with the transmission of the virus. (See Michael Grossman, Robert Kaestner and Sara Markowitz, 2005 for more information.)

The reduced form is the basic model for empirical estimation of STD rates. That is, the logged STD rate is regressed on the real state and federal tax on beer, the percentage of each state's population living in counties dry for beer, indicators for the presence of blood alcohol concentration (BAC) laws, an indicator for zero tolerance laws for underage drinking and driving, other characteristics of the population of the area, area effects and year effects. The state level variables are appended to the AIDS data based on the state or states represented by the MSA.

Two problems may arise in estimating the reduced form equation. First, the residual may be serially correlated if there exists unobserved state-specific time-varying factors. Persistent discrepancies in state reporting practices or screening programs might cause the error terms to be correlated across time within a state. We solve this problem 
by adopting the Marianne Bertrand, Esther Duflo, and Sendhil Mullainathan (2004) correction for serial correlation by computing robust standard errors that allow for clustering by area. The second problem arises if the incidence rate of communicable diseases depends on the past incidence or prevalence of the disease. This suggests that the lagged STD rate should be included in the equations. However, Badi H. Baltagi (2001) shows that the coefficient of the lagged dependent variable is biased in a fixed-effects model applied to a panel even if the disturbance term is serially uncorrelated. This bias will translate to bias in estimates of the effect of other regressors that are correlated with the lagged dependent variable.

To address this problem, we adopt alternative methods to account for the lagged dependent variable. The first is a reduced form equation which replaces the lagged STD rate with some of its determinants, and the second directly includes the lagged STD rate. The reduced form OLS equations include lagged beer taxes and percent dry as additional regressors. Models that include a lagged dependent variable apply a first-difference twostage least squares (FD2SLS) estimator (Baltagi 2001). The FD2SLS estimator is constructed by taking first differences of all variables and thereby eliminating area fixed effects. The lagged first-differenced STD rate is correlated with the first-differenced residual, hence, the second lag of the STD is employed as an instrument for the lagged first difference. When considering STDs, it is questionable as to what is the appropriate lagged rate to use. We test models that include alternatively the lagged dependent variable, which is gender specific, and models including the lagged total rate for both genders. Since the lagged total rate includes the lagged dependent variable, the model is still estimated by FD2SLS. 
The results are striking in that all models estimated reveal a negative and statistically significant relationship between the beer tax and male gonorrhea rates for both age groups. The result holds when the reduced form is estimated by OLS (with and without the lagged tax) and with a lagged STD rate included and estimated by FD2SLS. The OLS models give a tax elasticity of -0.47 for males ages $15-19$ and -0.41 for males ages 20-24. The magnitude of these effects fall slightly in the FD2SLS estimates to -0.44 for males 15-19 and -0.37 for males 20-24. A long-run effect can be calculated based on the coefficients on the tax and the lagged gonorrhea rate. For males in both age groups, the long run tax elasticity is -1.1 .

Higher beer taxes may also be effective in reducing AIDS rates for young males and females. The OLS models with and without the lagged tax rates show negative and statistically significant effects of the beer tax on AIDS rates, although the coefficients from the FD2SLS are statistically insignificant. However, the one-year lag in the AIDS rate does not contribute much to the models, suggesting that OLS is the preferred specification.

Larger percentages of the population living in dry counties do not appear to be important in lowering either STD rate. The same can be said for the BAC laws although zero tolerance laws, which are aimed at drivers under the legal drinking age, are associated with a decrease in the gonorrhea rate of males ages 15-19.

\section{Conclusions}

This research sheds some light on the nature of the causal relationship between risky sexual behaviors and alcohol consumption. Using individual level data on sexual 
behaviors and aggregate data on STDs, which are measurable outcomes of risky sexual practices, we can draw two firm conclusions. The first is that alcohol use appears to have no causal influence in determining whether or not a teenage has sex. However, the second conclusion is that alcohol use lowers contraception use among sexually active teens. The individual level data analyzing birth control use among sexually active respondents in conjunction with the results from the STD data support this causal explanation. The evidence that gonorrhea and AIDS rates may be reduced with policies such as higher beer taxes suggests that the pathway is through consumption, which in turn affects risky sexual practices and leads to a STD. 


\section{REFERENCES}

Altonji, Joseph G.; Elder, Todd E. and Taber, Christopher R. "Selection on Observed and Unobserved Variables: Assessing the Effectiveness of Catholic Schools.” National Bureau of Economic Research (Cambridge, MA) Working Paper No. 7831, August 2000.

Baltagi, Badi H. Econometric Analysis of Panel Data. England: John Wiley and Sons, 2001.

Bertrand, Marianne; Duflo, Esther and Mullainathan, Sendhil. "How Much Should We Trust Differences-in-Differences Estimates?" Quarterly Journal of Economics, February 2004, 119(1), pp. 249-75.

Centers for Disease Control and Prevention. $\underline{\text { Young People at Risk: HIV/AIDS }}$ among America's Youth. Atlanta, GA: U.S. Department of Health and Human Services, Centers for Disease Control and Prevention, 2002.

Centers for Disease Control and Prevention. Sexually Transmitted Disease Surveillance, 2002. Atlanta, GA: U.S. Department of Health and Human Services, Centers for Disease Control and Prevention, 2003.

Donovan, Catherine and McEwan, Robert. "A Review of the Literature Examining the Relationship Between Alcohol Use and HIV-Related Sexual Risk-Taking in Young People." Addiction, March 1995, 90(3), pp. 319-328.

Grossman, Michael; Kaestner, Robert and Markowitz, Sara. "Get High and Get Stupid: The Effect of Alcohol and Marijuana Use on Teen Sexual Behavior." Review of the Economics of the Household, December 2004, 2, pp. 413-441. 
Grossman, Michael; Kaestner, Robert and Markowitz, Sara. "An Investigation of the Effects of Alcohol Policies on Youth STDs," in Advances in Health Economics and Health Services Research, Vol. 16-Substance Use: Individual Behavior,

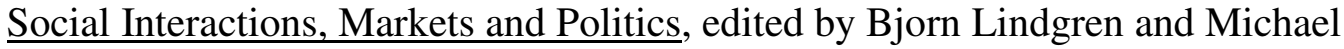
Grossman, Elsevier, Oxford, England, 2005.

Grossman, Michael and Markowitz, Sara. "I Did What Last Night?! Adolescent Risky Sexual Behaviors and Substance Use.” Eastern Economic Journal, Forthcoming. Ventura, Stephanie J. and Bachrach, Christine A. "Nonmarital Childbearing in the United States, 1940-99." National Vital Statistics Reports, October 18, 2000, 48(16), pp 1-39. 


\section{FOOTNOTES}

*Funding for this research was provided by grant number DA12692-03 from the National Institute on Drug Abuse to the National Bureau of Economic Research. 